\title{
XXXVI. On the effect of permanent elongation on the cross section of hard-drawn wires
}

\section{Professors T. Gray \& C. L. Mees}

To cite this article: Professors T. Gray \& C. L. Mees (1890) XXXVI. On the effect of permanent elongation on the cross section of hard-drawn wires, Philosophical Magazine Series 5, 29:179, 355-358, DOI: 10.1080/14786449008619947

To link to this article: http://dx.doi.org/10.1080/14786449008619947

曲 Published online: 08 May 2009.

Submit your article to this journal $\widetilde{x}$

Џ Article views: 2

Q View related articles $\square$ 
Table IX. (continued).

\begin{tabular}{|c|c|c|c|}
\hline \multicolumn{2}{|c|}{ Viscous Fluids. } & \multicolumn{2}{|l|}{ Solids. } \\
\hline Substance. & $\eta$ & Substance. & $\eta$. \\
\hline Marine glue .......... & $2 \times 10^{9}$ & 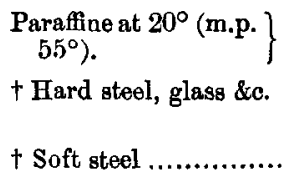 & $\begin{array}{l}>2 \times 10^{15} \\
\left\{\begin{array}{l}10^{17} \text { to } \\
6 \times 10^{17}\end{array}\right. \\
\left\{\begin{array}{l}6 \times 10^{17} \\
6 \times 10^{18}\end{array} \text { to }\right.\end{array}$ \\
\hline Range.............. & $10^{2}$ to $10^{11}$ & Range .................... & $10^{12}$ to $10^{20}$ \\
\hline
\end{tabular}

$\dagger$ During the first hour (500 to 3000 seconds) after twisting just within the elastic limits,

The limits here defined are somewhat arbitrary. They will be made more definite when a greater number of substances lying on the boundary between the classes have been examined. Information is lacking and particularly desirable in the neighbourhood of Andrews's critical temperature. From Table IX. it does not seem improbable that the critical temperature may be definable by a narrow limit of viscosity, quite apart from the substance operated on. What this limit may be I do not venture to assert, seeing that the viscosity of gases decreases on cooling, whereas that of liquids increases on cooling.

Table IX. gives the positively astounding range of variation of $\eta$, the chief variable of our material environment-a variable which throughout the whole enormous interval in question nowhere fails to appeal to our senses.

Phys. Lab., U.S. Geological Survey, Washington, D.C., U.S.A.

XXXVI. On the Effect of Permanent Elongation on the Cross Section of Hard-drawn Wires. By Professors T. GRat and C. L. Mess".

T $N$ the course of a series of experiments on the torsional 1 rigidity of metals, forming part of the course of instruction in elasticity in the mechanical laboratory of the Rose Polytechnic Institute, we were somewhat surprised to find a

* Read before the Physical Sociaty of Glasgow University, February 28, 1890. Communicated by Th. Shields, M.A., Secretary. 


\section{Profs. Gray and Mees on the Effect of Permanent}

hard-drawn iron wire increased in total rigidity by being slightly stretched above its elastic limit. Slight changes in the modulus of rigidity, due to stretching, are of common occurrence; but we had not previously noticed, nor heard of anyone else having noticed, such a change as to overbalance the effect of increased length and probably diminished section. The result seemed to make it probable that there was an actual increase of diameter produced by pull when the elastic limit is reached. As to whether actual permanent stretch is necessury to produce this effect we are not yet certain; but there seems, from subsequent experiments, little doubt but that, for soveral metals, hard-drawn wires do expand laterally when they begin to take a permanent longitudinal set.

The observation here referred to seemed so interesting, that we instituted careful observations on the effect of slight stretching (that is to say, permanent stretching of from to to $\frac{5}{10}$ of 1 per cent. of the original length) on the density of hard-drawn iron, brass, German silver, and pianoforte-steel wires. The results indicate that for an elongation of less than $\frac{1}{4}$ per cent. the section of the wire is slightly increased, above which the section diminishes. The experiment is, however, by this method exceedingly tedions and difficnlt, and hence the exact elongation which gives the greatest inerease of section has not been determined. One or two of the results are quoted below mainly for the purpose of indicating the magnitode of the quantiilies concerned. These changes are very small ; and as they enter into the experiments on density determined by weighing in water as the differences between quantities of comparatively large magnitude, we cannot assume the results to be more than an indication confirmatory of the result obtained from the elastieity experiments. It may be remarked, however, that experiments on this subject were made by several members of the senior class both on soft and hard wires, with the consistent result that they obtained sometimes a gain, sometimes a loss of density for the soft wire, but always a loss of density in the hard wires. The specimens which showed most docided results were cat frem two coils of very hard wire, one brass and the other German silver. The brass is so hard as to render it difficult to obtain permanent stretch without fracture. The results with iron and steel have not been quite so conclusive, owing to difficulties with oxidation during the density-determinations. A pianoforte-steel wire does, however, show signs of slightly increasing in volume just before breaking. The difference between the elastic strength and the rupturing strength is not great in pianoforte-wire, and it 
is difficult to avoid fracture. We hope, however, to make a more systematic investigation, and to get over these difficulties by improved apparatus and methods of experiment.

Confining our attention to the brass and German-silver wires, the results indicate that if the stretch does not amount to more than from ${ }_{20}^{1}$ to $\frac{1}{10}$ of 1 per cent. the diameter increases. The elastic effect previous to the point where stretching is about to begin is for those wires in accordance with other well-known results of experiments on this subject, in so far as the diameter diminishes with increase of length; but we have not yet got a means of measuring with such accuracy as to give quantitative results as to the ratio of contraction to extension. The change from contraction to expansion seems to take place very near to the limit of elasticity, if not after that limit has been reached. A short distance beyond this limit coutraction again sets in ; and if the extension be as much as half of 1 per cent., the diminution of density, although noticeable, is not sufficient to produce increase in diameter.

The method of experiment which was used for the observations on which we base some of the above remarks on the effect of elastic stretch, was to pass the wire along the axis of a glass tube about 5 millimetres in diameter, which was hung on the wire in the manner indicated in the sketch by means of a rubber stopper $s$. The tube was then filled with water, and the position of the surface of the water read on a scale fixed on the back of the tube. The wire was then stretched and the fall or rise of the water observed. A diminution of volume was observed until the wire reached about the elastic limit, at which point the water rose, slightly indicating a swelling of the wire. We have made several attempts to increase the sensibility of the above arrangement by means of index-tubes fused into the side of the main tube, aided by narrow contractions in the tube, itself filled with mercury, from which the wire was protected at that point by a thin coating of shellac varnish. As yet, however, we have not been perfectly successful. The unstable condition of the mercury in the narrow contraction of the tube renders this method unsatisfactory. Should mercury-tubes prove superior, however, in experiments with iron and steel, we will platinize the

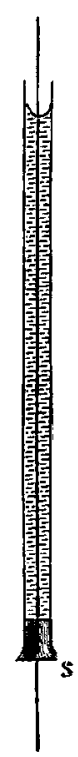
other metals and use mercury.

The following are a few of the results obtained by the measurement of density before and after stretching, the Phil. Mag. S. 5. Vol. 29. No. 179. April 1890. 2 E 
method being the determination of the loss of weight when immersed in water. Very careful precautions were taken to eliminate all trace of air from the wire and from the water by placing the vessel in the receiver of an air-pump and working the pump continuously for an hour or more. Care was also taken to minimize the effect of capillarity, and to correct for temperature in the measurements. Boiling the water by passing a stream of steam through it, causing a current to play on the wire, was also tried, with the result that the iron and steel wires tarnished too much to render the results of any great value. The effect of stretching was slightly diminished, a result which might possibly be due to annealing.

\begin{tabular}{|c|c|c|c|}
\hline Kind of Metal. & $\begin{array}{l}\text { Percentage } \\
\text { permanent } \\
\text { elongation. }\end{array}$ & $\begin{array}{l}\text { Areas of section } \\
\text { before stretching, } \\
\text { in square centim. }\end{array}$ & $\begin{array}{l}\text { Areas of section } \\
\text { after stretching, } \\
\text { in square centim. }\end{array}$ \\
\hline \multirow{2}{*}{ Brass } & $0 \cdot 10$ & 001262 & $0 \cdot 01268$ \\
\hline & $0 \cdot 20$ & $0 \cdot 01261$ & $0 \cdot 01269$ \\
\hline \multirow{2}{*}{ German-silver ... } & $0 \cdot 12$ & $0 \cdot 008255$ & $0 \cdot 008300$ \\
\hline & $0 \cdot 20$ & 0.00827 & 0.00834 \\
\hline
\end{tabular}

XXXVII. On the Passage of Electricity through Hot Gases. By J. J. Thomson, M.A., F.R.S., Cavendish Professor of Experimental Physics, Cambridge*.

G ASES exhibit the most remarkable differences of behaviour with respect to the passage of electricity through them: the same gas under different circumstances may be either an insulator and require the electromotive intensity to exceed a certain value before any electricity at all can pass through it, or it may be a conductor and unable to insulate even a difference of potential as small as 1000 of a volt (Blondlot, $C$. R. civ. p. 283). The study of the changes in the condition of the gas which accompany these remarkable changes in its electrical properties can hardly fail to afford most interesting information as to the method by which electricity passes through gases, and possibly through solids and liquids as well. As one of the simplest changes which can take place in the condition of a gas is that occasioned by a rise in tempe-

* Communicated by the Author. 